\title{
FOURIER E O BRASIL
}

\author{
Mauricio Vinhas de Queiroz ${ }^{1}$
}

RESUMO: O autor reconstitui a biografia de Charles Fourier e as origens do socialismo utópico na França, após a Revoluçảo francesa. Estuda as dissidências do primeiro falanstério fundado por discípulos de Fourier em Santa Catarina, em 1841, as vicissitudes das duas colônias iniciadas, Sá e Palmital e o fracasso desta última. Relata a influência de outro discípulo de Fourier, Dr. Louis Vauthier em Recife e sua atuação junto aos primeiros socialistas pernambucanos através da Revista. $O$ Progresso, que em 1846 já pregava a necessidade de uma reforma agrária no Nordeste.

Em 1841 desembarcava no Rio de Janeiro um curioso médico francês, o Dr. Benoit Mûre. Pouco sabemos sobre o seu passado. Era homem de novidades e aventuras, irrequieto e inteligente, alguns o julgavam charlatão. Vaga notícia veio até nós que, dois anos antes da sua viagem, inaugurara ele em Paris um estabelecimento de hidroterapia, onde explorou o método homeopático do Dr. Hanemann, então o sucesso da época. Desconhecemos, porém, se a empresa, por uma infelicidade qualquer, acabou fracassando, se o Dr. Benoit Mûre a transferiu com lucro, ou afinal em que deu. De uma forma ou de outra, ao pisar em terras brasileiras esse contemporâneo de Balzac, eram outros, bem diferentes, os seus interesses e planos.

Quase todos que tiveram oportunidade de referir-se a Benoit Mûre, e especialmente ao desempenho da missão que o trouxe ao Brasil, não esqueceram de falar nos seus "modos afáveis" ou na sua "eloqüência persuasiva". Disto ele sempre deu, na verdade, as melhores provas.

1 Depto. de Sociologia, Universidade de Brasilia. 
Vinha com uma idéia de doido. Pretendia convencer os austeros homens do governo imperial a consentir e auxiliar a instalação, aqui, de um "falanstério", a ser organizado por imigrantes franceses. Simplesmente, uma dessas colônias utópicas, através de cuja multiplicação espontânea sonhavam os adeptos de Fourier edificar, em todo o globo, a sociedade do futuro.

Benoit Mure visitou os nossos poderosos. Falou, insistiu, convenceu. Teve a sorte de conquistar a simpatia de um senhor influente, o brigadeiro Machado de Oliveira. E assim, após inúmeras peripécias, viu - como se diz recompensado o seu esforço. A Assembléia Geral fez esplêndida concessão de terras na península do Saí, para que nelas fosse estabelecido o tal "falanstério". Votou, ainda, uma ajuda de 64 contos de réis.

Não conseguimos reunir documentário suficiente para contar, com todos os detalhes, a surpreendente história dessa empresa, a sua fundação, as intrigas e lutas que em seu seio surgiram, tudo que alcançou de positivo e concreto, e, por fim, o fracasso, a derrocada. Com o pouco que temos é possível, no entanto, um leve esboço, o bastante para nos ajudar no estudo da influência exercida em nossa vida política e social, pelos discípulos de Fourier.

Antes de traçar o esboço da aventura fourierista em terras do Brasil, é bom recordar alguma coisa acerca das idéias que traziam consigo, ao chegar aqui, aqueles socialistas primitivos e sonhadores.

François Marie Charles Fourier nasceu em Lião, cidade de artífices e operários. Viveu a infância no tempo em que na França amadureciam as premissas da Grande Revolução. Adolescente, assistiu à queda do "antigo regime" e à aurora do predomínio burguês.

Filho de comerciantes, Charles Fourier, desde criança, odiou o comércio. Não tinha mais de seis anos quando percebeu que, na própria loja de seus pais, eram o fregueses torpemente ludibriados. Às escondidas, passou a advertí-los da fraude. Certo dia, foi delatado por um deles. E Charles levou então a maior surra da sua infância.

Através de toda a vida, exceto alguns anos antes de morrer, jamais conseguiu Fourier escapar ao gênero de vida que repugnava. Jovem ainda, 
percorreu meia Europa como caixeiro-viajante. Mais tarde e mpregou-se, em Paris, como simples correspondente, na firma norte-americana Curts \& Lamb.

Já naquela época, muitíssimos homens havia como Fourier, aos quais a profissão causava nojo e raiva; mas, cumpridores estritos do dever, metódicos e pontuais, até que lhes viesse a morte, por eles encarada como a suprema libertadora. Trazia Fourier, porém, no mais íntimo do ser, um demônio oculto, que nele não levava ao alcoolismo, nem às aventuras galantes, nem tampouco à fuga na poesia. Levava-o a procurar o que existia de errado na estrutura da vida social, de tão errado que ele próprio, como tantos outros, não estava onde desejaria, e sim proibido de realizar-se totalmente, viver de acordo com sua vontade, seus impulsos.

A princípio, nas raras horas de descanso, entregava-se Fourier às mais diversas e surpreendentes aventuras do espírito. Inventou, por exemplo, um sistema "sui-generis" de ensinar música, uma nova espécie de estrada de ferro e toda uma teoria urbanística. Mais tarde é que se definiu, por inteiro, a sua vocação de crítico do sistema social.

Não se limitou, entretanto, Charles Fourier a apontar os defeitos, os erros fundamentais da sociedade que se levantava sobre os escombros do mundo feudal. Não entrou a aconselhar uma "volta ao passado". Empenhou-se em procurar uma solução real, e acreditou encontrá-la com o seu "falanstério".

Fourier é, ao mesmo tempo, racionalista e místico. Em parte, descendem suas teorias, linha direta, dos enciclopedistas Diderot, Montesquieu, Rousseau. Mas entre eles e Fourier há, de permeio, um acontecimento cuja importância ninguém pode obscurecer, a Revolução francesa.

Quando os enciclopedistas se lançavam contra as instituições feudais, o critério único era a "razão". Aquelas instituições não se justificavam porque não eram racionais, e sim contrárias à natureza humana e à própria natureza cósmica.

Desencadeada a Revolução, triunfante o capitalismo, implantado o novo regime, estaria, pois, instaurado o reino da Razão? Ao contrário. A liberdade, para a grande massa, agora significava ser livre apenas para vender a este ou aquele dono de fábricas a força de seus braços. Os trabalhadores não eram mais servos de um único senhor, mas se transformavam em escravos de toda a classe burguesa em seu conjunto. A igualdade se restringia ao "tratamento igual em face da lei". A fraternidade universal, desmentia-a a exploração do homem pelo homem, ainda mais intensificada, o açambarcamento e a especulação com a fome das multidões, a riqueza de uns poucos à custa do empobrecimento da grande 
maioria. Isto, sem falar nas guerras que se espalhavam com ímpeto desconhecido, pela Europa inteira.

A crítica de Fourier não se atem aos aspectos exteriores da nova forma de vida. É raro encontrar, na sua extensa obra, referências aos acontecimentos históricos que ele presenciou: a Revolução Francesa, as conquistas de Napoleão, a Restauração, a revolução de 1830 . Fourier, o que examina, são os fundamentos econômicos e a estrutura social da época que se inicia. Neste particular, faz incidir não apenas a crítica, mas a sátira: tem gênio ardoroso e mordaz, agudo e sarcástico. Rejeita a sociedade contemporânea por considerá-la monstruosa. É desorganizada, irracional, presa do capricho, da força e da fraude. Ao notar que o desenvolvimento da técnica e dos processos de produção, longe de trazer a fartura, traz desgraças maiores para a grande massa, exclama que "a pobreza brota da própria abundância". Analisa com minúcia todas as instituiçốes do tempo. Sobre o casamento e a situaçào da mulher possui páginas de factura definitiva. Dele é o aforisma de que o grau em que a mulher está emancipada, em uma sociedade constitui o barômetro natural por que há de medir-se a emancipação do conjunto.

Fourier divide a história da humanidade em fases de sucessiva mudança: a selvageria, o patriarcado, a barbárie e a civilização. Pensa ter encontrado - e aí já nos defrontamos com os traços místicos de sua teoria - misteriosas relações, ou melhor, a necessidade de uma "harmonia" entre o corpo do homem e a matéria cósmica, entre a alma humana e o espírito do Universo. No seu estado de "civilização", que, para ele, corresponde ao regime capitalista, - a sociedade não se rege de acordo com as "leis da atração universal". Assim não só o homem se torna infeliz e diminuído, mas o próprio Universo padece e enferma.

Segundo Fourier, a personalidade do indivíduo vem definida ao nascer. Classificam-se as personalidades de acordo com a predominância, ou a maneira de combinação, na alma da pessoa, de doze paixões fundamentais. $\mathrm{Na}$ "civilização", as coisas se encontram dispostas da tal maneira, que é proibida a satisfação normal dos desejos mais legítimos. As paixões conduzem a uma luta consigo mesmo e com os demais. Na sociedade "harmônica", ao contrário, esses conflitos desaparecerão. Os impulsos, sentimentos e aptidões serão de tal maneira orientados que, mesmo aqueles hoje considerados inúteis ou prejudiciais, encontrarão forma de se manifestar em benefício da sociedade.

Para passar dessa atual "civilização", desorganizada e caótica, ao estado de "harmonia", basta conhecer o segredo da "atração universal". Restabelecido 
o equilíbrio entre a sociedade e o Universo, não apenas o homem viverá no reino dos céus, mas o próprio mundo readquirirá a sua saúde perdida. Novas espécies de plantas e animais aparecerão, e tudo se tornará melhor e mais belo.

E ele acredita haver descoberto o máximo segredo. Faz detalhada e extensa classificação dos caracteres humanos. Partindo daí, estabelece o plano de uma pequena sociedade, em que todos esses caracteres estejam representados, e combinados de tal maneira, que uns se completem aos outros. Já estamos vendo, nessa pequena sociedade, o "falanstério", célula-mater da nova vida social.

O "falanstério" deve se localizar nuns $\mathbf{5 . 0 0 0}$ acres de terra, em local de colinas e com água corrente. Mil seiscentos e vinte é o número ideal de pessoas que devem compor tal unidade, mas o limite pode ser tomado menos rigidamente. Todos devem morar em uma só casa coletiva, verdadeiro palácio. As refeições se preparam na cozinha comum, e todos os serviços, desde a agricultura aos de mais alto teor intelectual são prestados mutuamente por grupos de especialistas. No "falanstério", cada qual, agindo e trabalhando de acordo com as suas tendências inatas, contribui de modo espontaneo para o bem estar do conjunto.

Claro que, ao passar da atitude crítica à definição de normas e à atividade concreta, muda automaticamente a posição de Fourier - como a dos demais socialistas utópicos. Fourier não percebeu a dinâmica interna do movimento social. Despreza a luta política, e ignora o papel histórico reservado ao proletariado na destruição do capitalismo e na edificação de uma sociedade nova, "racional e harmónica". Mesmo porque o proletariado não havia ainda se definido, a seu tempo, como "classe para $\mathrm{si}^{\text {". }}$

Fourier e os demais construtores de utopias pensavam pôr em prática os seus planos com apelos ao coração dos poderosos e à bolsa dos burgueses, justamente os beneficiários do regime que anatematizavam. E, quando conseguiam, eles ou seus discípulos, inaugurar um dos seus fantásticos empreendimentos é sempre para vê-lo ruir como árvore de raízes podres, frágil ao advento da realidade.

Tornaram-se famosas e bem conhecidas as tentativas de Victor Considerant, no sentido de fundar um "falanstério" em San Antonio, Texas, Estados Unidos. Datam elas de 1852. Anteriores, são as que foram realizadas aqui mesmo em nossa terra, sobre as quais, entretanto, muito pouco se tem falado. 
Em 1840, se organizou na França uma "Union Industrièlle", cujo objetivo era arregimentar pessoas dispostas a instituir um "falanstério" no Brasil. À frente da empresa encontrava-se um certo Dr. Arnaud.

Enquanto se constituíam, em Paris e Lião, os grupos de colonos, partia na frente o dr. Benoit Mure, com atribuições de negociar junto ao nosso governo a licença e a concessão de terras.

Mure não demorou a noticiar o bom êxito de sua missão. E embarcou para cá a primeira leva de voluntários. Eram, em geral, famílias de trabalhadores, gente que não vivia satisfeita com o estado das coisas. $O$ grupo inicial compreendia uns cem indivíduos. Elegeram para dirigí-los Michel Derrion.

Ao desembarcarem no Rio - princípios de 1842 - Mure foi apresentá-los pessoalmente a Pedro II. Alegres e esperançados, viajaram depois para Santa Catarina, onde se instalariam no extenso terreno concedido pela nossa Assembléia Geral.

Na península do Saí, começou a estabelecer-se o Falanstério d'Oliveira. O nome representava uma deferência ao Brigadeiro, protetor de Mure. Mal iniciavam os trabalhos, graves desavenças foram, porém, surgindo entre os homens. Onde as misteriosas leis da "harmonia universal"? Onde o ajustamento das paixões e dos caracteres?

Formou-se um grupo sob a liderança de Benoit Mure, hostil ao que se congregou em torno de Michel Derrion. Houve até mesmo tentativas de assassínio de um e de outro desses dois cabeças.

A tal ponto chegaram as dissidencias, que Derrion e os seus resolveram abandonar a península do Saí. Subiram o rio do mesmo nome, até um lugar de mata virgem chamado Palmital. Ali se entregaram à obra de fundar um novo "falanstério", providenciando, paralelamente, junto ao governo brasileiro, a devida autorização, o que conseguiram em março de 1843.

Nisto, chega a notícia de que está para desembarcar a segunda leva de colonos, sob a direção do serrador Jamain. Composto de 117 pessoas, vem ela no brigue "Virgínia". Ao atracar o navio no porto de São Francisco, já era aguardado por emissários do Palmital e do Saí.

Tão aguda e venenosa se mostrou a contenda entre aqueles propagandistas de "uma vida nova e harmônica", que a maior parte dos imigrantes logo se desiludiu. Muitos resolveram reembarcar de volta. Outros se dispersaram ali mesmo. Apenas quatro - entre os quais Jamain - se dirigiram para o Palmital, e 
27 outros para o "falanstério" d'Oliveira. Iam todos, porém, ressabiados e indecisos.

A terceira leva, que Joseph Reynier, pacientemente, estruturava em Lião, viu-se na contingência de nấo embarcar, pois não eram animadoras as notícias das brigas intermináveis.

Que conseguiram fazer de concreto, a despeito de suas contendas, os discípulos de Fourier em terras do Brasil? Qual o futuro dos "falanstérios" do Palmital e do Saí?

Em Palmital, após derrubar a mata, os colonos lavraram e semearam o solo virgem, para o próprio sustento. Campos de cereais foram bem cultivados, e chegou-se a plantar um pomar de árvores da Europa. Construíram uma casa de moradia em comum, e estradas com pontes e valados. Deram inf́cio a vários trabalhos hidráulicos para o aproveitamento do rio Saí. Sob a direção de Jamain, foi organizada uma serraria, e a colonia levantou um pequeno estaleiro naval. Com a venda das embarcações encontravam boa fonte de renda.

Não se conseguiu, porém, uma atmosfera feliz e sossegada: os desentendimentos internos eram cada vez mais constantes, os homens não se adaptavam àquela espécie de vida, em terras estranhas e bases tão diferentes. Pensaram que iriam logo entrar no reino dos céus, e o que os aguardava era trabalho árduo, dificuldades a resolver, problemas a enfrentar. Foram, aos poucos, desistindo, despediam-se desiludidos. Em 10 de outubro de 1843 , reuniram-se os que restavam para celebrar o aniversário da morte de Fourier. Eram apenas sessenta, entre homens, mulheres e crianças. Pouco mais duraria o empreendimento do Palmital.

O Falanstério d'Oliveira teve existência mais longa. Em fevereiro de 1844 recebia mais 120 colonos, entre lenhadores, carvoeiros e agricultores. Sob as vistas do ativo Benoit Mûre, inaugurou-se uma oficina de móveis, que passaram a ser exportados para o Rio de Janeiro. Fabricavam-se ainda moinhos de descascar arroz e outros objetos, também pàra comércio.

A 7 de abril de 1846, a colônia do Saí, bem ou mal, quatro anos e meio depois de fundada, continuava vivendo. Com o fracasso da outra, a do Palmital, o seu chefe, Michel Derrion, tinha vindo para o Rio, onde trabalhava como professor. Fez as pazes, nesta data, com a sua velha inimizade, o Dr. Benoit Mûre.

Apesar de todas as desgraças, inabalável continuava a fé de Michel Derrion nas doutrinas de Fourier. Transcorria justamente o aniversário natalício do pensador lionês, comemorado, mesmo depois de sua morte, pelos discípulos, 
como parte da liturgia da seita. Entre nós, na Côrte de São Sebastião do Rio de Janeiro, já havia, naquele 1846, um fervoroso grupo de convertidos ao socialismo utópico, por obra, em grande parte, do próprio Michel Derrion. E o grupo socialista organizou um banquete, para o qual foi convidado, em caráter especial, o dr. Benoit Mûre.

A reconciliação entre os dois foi sincera. Um espetáculo tocante. Em seu discurso, Mûre referiu-se às possibilidades da colônia do Saí; mas, já se notava em sua voz, outrora tão audaciosa, um tom veladamente pessimista, e isto era o prenúncio do fracasso, que não tardaria.

Os fourieristas franceses deixaram marcas bem firmes no Brasil. Além das experiências malogradas, fizeram surgir, por sua influência, um movimento de idéias, que da capital do Império se espalhava para as províncias. Devido à ação deles fundou-se entre nós um jornal pioneiro: OSocialista, em 1845. No mesmo ano, aparecia em Niterói o O Socialista da Província do Rio de Janeiro. Trabalhos de divulgação do fourierismo foram editados, aqui mesmo, em português, como o curioso folheto de Abel Tranzon (antigo discípulo da Escola Politécnica, engenheiro de minas): Teoria Societária de Carlos Fourier ou Arte de Estabelecer em todos os países associações domésticas agrícolas, de 400 a 500 familias.

O conhecimento dessa agitação socialista utópica entre nós, ainda em meados do século passado, abre vasto campo para as pesquisas históricas. Seria interessante precisar qual a sua influência sobre os ideais, ainda na infância, da burguesia revolucionária, e também sobre os primeiros passos de nosso movimento operário, cujo aparecimento em cena se faria poucos anos depois, com a greve dos tipógrafos de 1858 .

Meses antes do dr. Benoit Mûre pisar pela primeira vez a nossa terra, chegava ao Recife um engenheiro, francês como ele e também adepto das doutrinas de Fourier, embora não muito empenhado em aplicá-las na prática. Queremos aqui nos referir a Louis Séger Vauthier, cujo diário íntimo - um século depois - foi publicado em nossa língua, com prefácio e notas de Gilberto Freyre.

Trabalhando como engenheiro das Obras Públicas da Província de Pernambuco, Vauthier mantinha-se informado sobre o movimento fourierista em todo o mundo. Revela-nos o seu diário, embora geralmente nele só fossem 
consignados fatos da vida privada, $o$ interesse que lhe despertou a aventura do Saí.

Desta maneira, ficamos sabendo que, já em setembro de 1841, Vauthier procurara pessoas de recursos, que poderiam ser simpáticas à causa, para pedir-lhes auxílio à obra de Benoit Mûre. Embora o ajudasse, Vauthier tinha lá suas idéias formadas a respeito do ativo compatriota. Escreve ele no memorial: "Mûre é um charlatão, mas enfim sabe usar da língua e das palavras melífluas."

Perto de um ano depois, registra haver enviado para a Europa um "impresso de Mûre", que não conhecemos e cujo estudo seria, com certeza, de grande importância para a reconstrução mais precisa da história do Falanstério d'Oliveira. Trata-se, segundo informa o engenheiro, de uma certa "memória sobre a colônia de mecânicos franceses".

É por esta mesma época que Vauthier introduz em Pernambuco uma revista de propaganda das doutrinas de Fourier: Vemo-lo coligir assinaturas para A Phalange, que se edita em Paris. O primeiro assinante de quem fala é o Barão da Boa Vista. Mais tarde, Vauthier introduziria entre nós outro órgâo divulgador de novas idéias: Democratie.

Tal como Derrion conseguiu converter à sua fé certo número de pessoas na capital do país, tal como se espalhou e desenvolveu aqui na Corte a influência "socialista", também no Recife se mostrou notável esse mesmo processo. Melhor do que no Rio, conhecemos em Pernambuco, documentadamente, fatos que nos mostram como as idéias de Fourier serviram para desenvolver a consciência da burguesia revolucionária local, em luta contra os velhos senhores de terra.

Vauthier foi amigo de Antonio Pedro de Figueiredo, professor e jornalista, mulato e livre pensador, talvez o primeiro brasileiro a esboçar uma crítica segura de nosso sistema latifundiário, e apontar soluções concretas para a derrubada de tal sistema.

Das mãos de Vauthier, muitas vezes A.P. de Figueiredo recebeu $O$ Socialista, que se editava no Rio. Por sua vez, Vauthier colaborava em $O$ Progresso, revista da qual era Figueiredo redator-chefe. $\mathrm{O}$ primeiro número de O Progresso, Vauthier, com mostras de entusiasmo, tinha-o enviado para França, a seus companheiros de credo e a sua família.

Justamente nesta revista o mulato livre pensador se lançava contra a existência de nossas "grandes propriedades, fragmentos das antigas sesmarias, das quais mui poucas hão sido subdivididas". 
"O proprietário ou rendeiro - declarava aí Figueiredo ocupa uma parte delas, e abandona, mediante pequena paga, o direito de permanecer noutra e de cultiva-la a cem, duzentas e algumas vezes a quatrocentas familias de pardos ou pretos livres, dos quais ele se torna o protetor natural, mas deles também exige obediência absoluta, e sobre eles exerce o mais completo despotísmo. Daí resulta que as garantias da lei não são para esses mal-aventurados, que entretanto compóem a maior parte da população da província, mas para estes proprietários, dos quais três ou quatro, reunidos pelo laço de sangue, da amizade ou da ambição, bastam para aniquilar, numa vasta extensão de terras, as forças e a influência do governo".

É ainda em $O$ Progresso que o amigo do fourierista Vauthier lança, pela primeira vez entre nós, a idéia da divisão dos latifúndios e a entrega da terra aos que a trabalham:

"E mister que os individuos pouco abastados possam obter terras e cultivá-las com a certeza de gozar dos produtos, condições que hoje não existem, porque os senhores de engenhos e de fazendas se recusam obstinadamente d venda de qualquer porção dessa terras, fonte e garantia do seu poder feudal, e porque o desgraçado morador que se arrisca a plantar fica à mercê do proprietário, que o pode despedir de suas terras dentro de 24 horas."

Vemos, desta forma, que A. P. de Figueiredo, longe de ser um discípulo ortodoxo de Fourier, apenas serviu-se das teorias do utopista francês, para ajudar-se a si mesmo. Ao invés de apegar-se a fórmulas rígidas e secas, encarou de frente a vida social de nosso país, e procurou resolver problemas concretos q̣ue se apresentavam já àquela época; os mesmos até hoje, na sua essência latifúndio e exploração dos trabalhadores rurais - continuam desafiando nossos esforços.

Se aqui, em nossa terra, tiveram os adeptos de Fourier, com as tentativas do "falanstério", uma das primeiras comprovações práticas, em todo o mundo, da inoperância de suas soluções irreais e fantásticas, deixaram também sementes de inconformismo e ação revolucionária, cuja importância sabemos valorizar os que lutamos hoje por um Brasil melhor. 


\section{BIBLIOGRAFIA}

1. ARMAND et MAUBLANC. Fourier. Paris: Sociales Internacionales, 1937. 2. PONCE; Anibal. En el Centenario de Fourier. In: El Viento en el Mundo. Buenos Aires: Lib. y El Ateneo, 1939.

3. ENGELS, F. Do Socialismo Utópico ao Socialismo Científico.

4. ST. HILAIRE, Auguste. Viagem à Província de Santa Catarina. Tradução e notas de Carlos Costa Pereira. São Paulo: Nacional, s.d.

5. Amaral, Luís. História da Agricultura Brasileira. São Paulo: Nacional, s.d. 6. Gaumont, Jean. Histoire Générale de la Coopération en France. Paris, s.d. 7. Diário Intimo do Engenheiro Vauthier. Rio de Janeiro: M S., 1940.

8. O Socialista da Província do Rio de Janeiro, n² 1, 2 e 3, 1845.

ABSTRACT: The author traces Charles Fourier's biography and the beginnings of french utopic socialism, focusing on its repercussions in Brazil, where in the southern province of Santa Catarina were founded two colonies from an early dissidence among the first Fourierist immigrants. The article relates the difficulties faced by the colony of Sai and the eventual failure of Palmital. Finally, he studies Fourier's influence among Pernambuco's first socialists through the activities of a french doctor, Louis Vauthier and his influence in the socialist periodical $O$ Progresso, which preached already in 1846 an agrarian reform against the northeastern's powerful and owners. 